\title{
Heterogeneous Microstructure-Induced Creep Failure Responses in Various Sub-Zones of Modified 310S Welded Joints
}

\author{
Yunlu Jiang ${ }^{1,2}$, Ying $\operatorname{Kan}^{1}$ and Huaining Chen ${ }^{1, *}$ \\ 1 Key Laboratory of Nuclear Materials and Safety Assessment, Institute of Metal Research, Chinese Academy \\ of Sciences, Shenyang 110016, China; yljiang@imr.ac.cn (Y.J.); ykan@imr.ac.cn (Y.K.) \\ 2 School of Materials Science and Engineering, University of Science and Technology of China, \\ 72 Wenhua Road, Shenyang 110016, China \\ * Correspondence: hnchen@imr.ac.cn
}

Citation: Jiang, Y.; Kan, Y.; Chen, H. Heterogeneous MicrostructureInduced Creep Failure Responses in Various Sub-Zones of Modified 310S Welded Joints. Metals 2022, 12, 116. https://doi.org/10.3390/ met12010116

Academic Editor: Byeong Choon Goo

Received: 13 December 2021

Accepted: 5 January 2022

Published: 7 January 2022

Publisher's Note: MDPI stays neutral with regard to jurisdictional claims in published maps and institutional affiliations.

Copyright: (C) 2022 by the authors. Licensee MDPI, Basel, Switzerland. This article is an open access article distributed under the terms and conditions of the Creative Commons Attribution (CC BY) license (https:// creativecommons.org/licenses/by/ $4.0 /)$.

\begin{abstract}
In order to reveal the creep failure behavior of novel modified 310S austenite steel welded joints, the creep life and microstructure evolution of the $310 \mathrm{~S}$ austenite steel welded joints were investigated in this study. The rupture life was assessed to estimate the damage of the welded joint based on creep rupture tests performed at $600{ }^{\circ} \mathrm{C}$ in the stress range of $170-238 \mathrm{MPa}$. Compared with WM, HAZ facilitated the occurrence of creep failure in long term creep due to the combination of a smaller hardness value, a more heterogenous microstructure accompanied by coarsened $\mathrm{M}_{23} \mathrm{C}_{6}$, a larger grain size, higher KAM and Schmid factor. Discontinuous Laves phases appeared near the boundaries between the $\delta$-ferrite and $\gamma$-austenite grains in the $\mathrm{WM}$, and dislocation strengthening and precipitation strengthening were observed near the boundary in the BM. Furthermore, segregation elements were detected by APT and EDS adjacent to the boundary. Cr and C segregation near grain boundaries weaken the creep resistance in long term creep service.
\end{abstract}

Keywords: heat-resistant stainless steel; welded joint; creep rupture; microstructure evolution

\section{Introduction}

AISI 310 austenitic stainless steel is one of the most promising materials for use in the key components of nuclear power plants or chemical industries, owing to its prominent comprehensive properties, such as excellent high temperature creep resistance and corrosion resistance [1,2]. However, owing to the inherent microstructure heterogeneity, the $310 S$ welded joints are easily subject to premature failure during creep service at elevated temperatures for long periods. Some of the literature is focused on the failure behavior of welded joints [3,4]. Therefore, the creep failure of welded joints is essential.

Since the $310 \mathrm{~S}$ welded joint in nuclear power plants is intended to service above $600{ }^{\circ} \mathrm{C}$ in its design application, the properties of creep deformation and rupture are crucial to service life and safety [5]. Despite wrought development, premature failure attributed to welded joints has plagued the nuclear power industry for decades, and there is still no proper solution. Thus, we should be pay more attention to the creep performance of welded joints at high temperatures. High-temperature creep properties are strongly linked to the nucleation, growth, coarsening and dissolution of different precipitates [6,7]. Precipitation strengthening plays a significant role in creep resistance [8,9]. In stainless steels subjected to elevated temperature, the precipitation of $\mathrm{M}_{23} \mathrm{C}_{6}$ and $\delta$-phase particles is considered to be detrimental and can eventually cause cracking of the material [10,11]. Depending on ageing time, precipitation could decrease the yield strength due to the competition between locally reduced solid solution strengthening and precipitation strengthening [12-14]. It should be stressed that $\mathrm{M}_{23} \mathrm{C}_{6}$ precipitation often plays an important role for the hightemperature materials, such as stainless steels, nickel-based super alloys and other alloys, 
used in components of super heater boilers and supercritical heat exchangers operating at temperatures above $600{ }^{\circ} \mathrm{C}$ [15-17]. A cube relationship between the $\mathrm{M}_{23} \mathrm{C}_{6}$ precipitates and the matrix of [001] $\gamma||$ [001] M23C6 and [110] $\gamma||$ [110] M23C6 has been reported, whereby the adjacent grain boundary is likely prompted into nucleation by minimizing the activation energy [18-20].

In the normal cases, joint softening, creep cavities and cracks are essential for creep failure during creep exposure [5,21]. Isik et al. found that Laves phase particles were apt to nucleate around $\mathrm{M}_{23} \mathrm{C}_{6}$, which implies that the evolution behavior of second-phase particles should be assessed in creep service [22,23]. Liu et al. revealed that the creep failure of $9 \mathrm{Cr}$ dissimilar welded joints in an over-tempered zone (OTZ) failed from stress concentration, which was induced by the coarsening of $\mathrm{M}_{23} \mathrm{C}_{6}$ in triple grain boundaries [24]. Due to the microstructure heterogeneity of welded joints, the creep failure behavior of welded joints under the service period should be of concern. However, most of the researchers concentrate on creep crack growth and the effect of heat treatment on welded joints $[25,26]$. Few researchers have paid attention to the fracture behaviors, specifically considering the integrity of welded joints under different applied stresses. Therefore, it is important to assess creep failure behavior in order to systematically explain the creep cracking and rupture failure behaviors of each zone of a $310 \mathrm{~S}$ welded joint.

Meanwhile, experimental data on the microstructure and rupturing of plasma arc welding (PAW) welded joints under elevated temperature conditions are still scarce. Thus, the purpose of this paper is to make clear the creep failure behavior in each region of a PAW welded joint. In this research, a series of creep experiments were carried out on the welded joints at $600{ }^{\circ} \mathrm{C}$ and with a stress range of 238-170 MPa. The evolution of the heterogeneous microstructure was characterized in detail by using optical microscope (OM), scanning electron microscope (SEM), electron back-scattered diffraction (EBSD) and transmission electron microscope (TEM), which could be used to make clear the relation between failure location and crack behavior. The evolution of the heterogeneous microstructure was characterized in detail, and found to be caused by the creep condition. Based on the creep resistance and microstructure characterization, the creep failure behavior of the sub-zones of the 310S welded joint was fully analyzed and clarified. The results acquired from this study could be applied to evaluate the structural integrity of the components, especially the glass curing container.

\section{Materials and Testing}

\subsection{Materials and Welding Procedure}

A $6.5 \mathrm{~mm}$ thick X9CrNiSiNCe21-11-2 austenitic stainless steel plate, named modified 310S, was used as the base metal (BM) to produce welded joints via PAW. The filler material was $25 \mathrm{Cr}-20 \mathrm{Ni}$ welding wires, with a diameter of $1.2 \mathrm{~mm}$. The $310 \mathrm{~S}$ billets were reheated to $1200{ }^{\circ} \mathrm{C}$ for $60 \mathrm{~min}$, hot rolled from $50 \mathrm{~mm}$ to a $6.5 \mathrm{~mm}$ thick plate. The heat-treatment solution condition of the plate is $1050{ }^{\circ} \mathrm{C}$ for $20 \mathrm{~min}$, followed by final water quenching. Specimens for the creep rupture test were taken from the plates parallel to the rolling direction. The main chemical compositions of the BM and filler materials are listed in Table 1. PAW procedure was performed by single-layer and single-pass techniques with I-groove and no gap. The welding current was $160 \mathrm{~A}$, welding voltage was $25 \mathrm{~V}$, and the welding speed was $15 \mathrm{~mm} / \mathrm{s}$. The $310 \mathrm{~S}$ welded joint was extracted from a mockup of the welded plate. The $310 \mathrm{~S}$ welded joint without phase transformation strengthening, and the curing container is not easy to achieve for post weld heat treatment (PWHT). Therefore, the welded joint did not use PWHT in this work. The microstructures are shown in Figure 1. The vermicular ferrite was inserted at the dendritic grain boundaries of the austenite matrix, as shown in Figure 1a. However, the heat affected zone (HAZ) has an obvious border produced by the immense influence of the welding thermal cycle, as shown in Figure $1 \mathrm{~b}$. The isometric austenite matrix is shown in Figure 1c. The metallographic differences will manifest different creep resistances. The uniaxial tensile tests were conducted by the SANSCMT machine (CTMI Co., Ltd, Shenzhen, China). The samples were tested with tensile 
displacement rates ranging from $0.2 \mathrm{~mm} / \mathrm{min}$ to $2 \mathrm{~mm} / \mathrm{min}$ at room temperature and $600{ }^{\circ} \mathrm{C}$. Figure 2 shows that serrations appeared in the stress-deformation curve of the welded joints at $600{ }^{\circ} \mathrm{C}$, indicating that the welded joints experienced dynamic strain aging at this temperature. The values of tensile strength and yield strength were $660 \pm 20 \mathrm{MPa}$ and $350 \pm 10 \mathrm{MPa}$ at room temperature, and $410 \pm 20 \mathrm{MPa}$ and $200 \pm 10 \mathrm{MPa}$ at $600{ }^{\circ} \mathrm{C}$, respectively.

Table 1. The main chemical compositions of BM and filler materials (wt.\%).

\begin{tabular}{cccccccccccccc}
\hline Elements & $\mathbf{C}$ & $\mathbf{C r}$ & $\mathbf{N i}$ & $\mathbf{M n}$ & $\mathbf{M o}$ & $\mathbf{S i}$ & $\mathbf{C o}$ & $\mathbf{V}$ & $\mathbf{N b}$ & $\mathbf{C e}$ & $\mathbf{T a}$ & $\mathbf{F e}$ \\
\hline BM & 0.10 & 20.5 & 11.1 & 2.0 & 0.05 & 2.20 & 0.10 & 0.08 & 0.03 & 0.04 & $/$ & Bal. \\
Filler materials & 0.09 & 26.4 & 21.8 & 2.0 & 0.35 & 0.38 & 0.20 & 0.08 & 0.05 & $/$ & 0.20 & Bal. \\
\hline
\end{tabular}
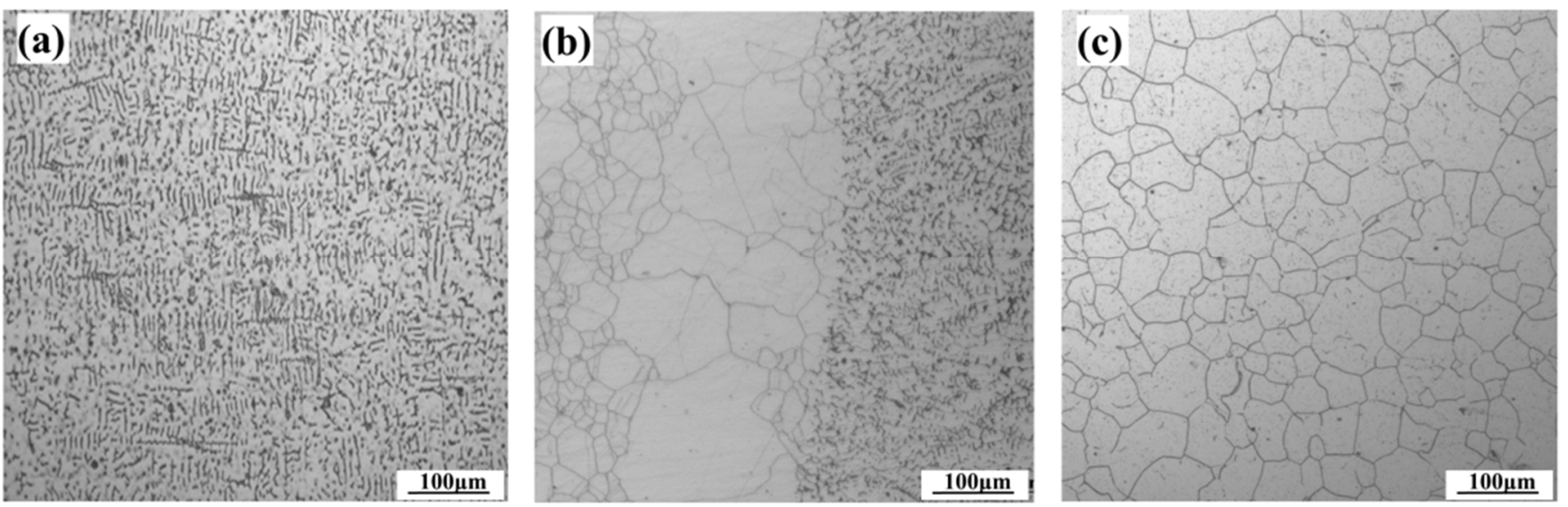

Figure 1. Metallographic morphology of $310 \mathrm{~S}$ stainless steel welded joints (a) WM (b) HAZ and (c) BM.

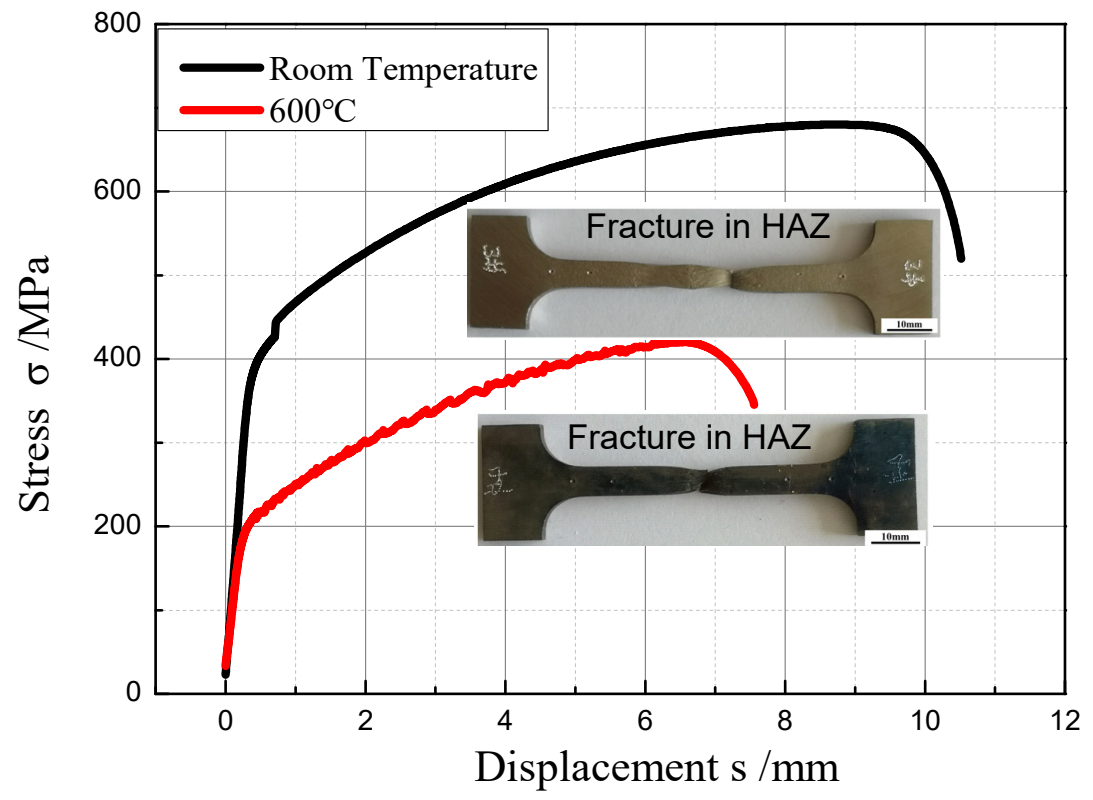

Figure 2. The stress-displacement curve of the welded joints. 


\subsection{Creep Experiment}

Standard creep rupture specimens, according to the ASTM E139 standard, with a $10 \mathrm{~mm} \times 3 \mathrm{~mm}$ cross-section and $50 \mathrm{~mm}$ gauge length, were used in this study. The specimens were taken from the BM of the welded joint where the weld metal (WM) was in the middle of the specimen. The creep properties were tested by using a series of uniaxial testing over a series of stresses from $238 \mathrm{MPa}$ to $170 \mathrm{MPa}$ at $600{ }^{\circ} \mathrm{C}$.

The hardness distribution, creep cracking and microstructure evolution were also assessed in the creep evaluation. The secondary phases, mainly the $\mathrm{M}_{23} \mathrm{C}_{6}$ and Laves phases, were given special attention in the microstructure analysis of the welded joints. An etching reagent consisting of $10 \%$ oxalic acid was used to reveal the austenite and ferrite phases. The micro-hardness measurements were carried out on sections perpendicular to the welding direction, with a load of $1 \mathrm{~kg}$ for $13 \mathrm{~s}$, to evaluate the micro-hardness distribution of the welded joints. Subsequently, the microstructures were characterized by using a Zeiss Axio Observer Z1 (Zeiss, Jena, Germany), an FEI QUANTA 450 (FEI, USA), and an EBSD (ZEISS MERLIN Compact, Jena, Germany). Chemical composition analysis of phases was performed by atom probe tomography (LEAP 4000, APT, France). Moreover, TEM (FEI Tecnai G2 20, Hillsboro, ORE, USA) was employed to acquire more details of the precipitates in the creep microstructure.

\section{Experimental Results and Analysis}

\subsection{Fracture Location and Morphology}

To detect the creep properties of $310 \mathrm{~S}$ welded joints, the creep rupture life was explored under the tensile stresses from $238 \mathrm{MPa}$ to $170 \mathrm{MPa}$ at $600{ }^{\circ} \mathrm{C}$, as shown in Figure 3. Creep rupture occurred in HAZ under different stress loads.

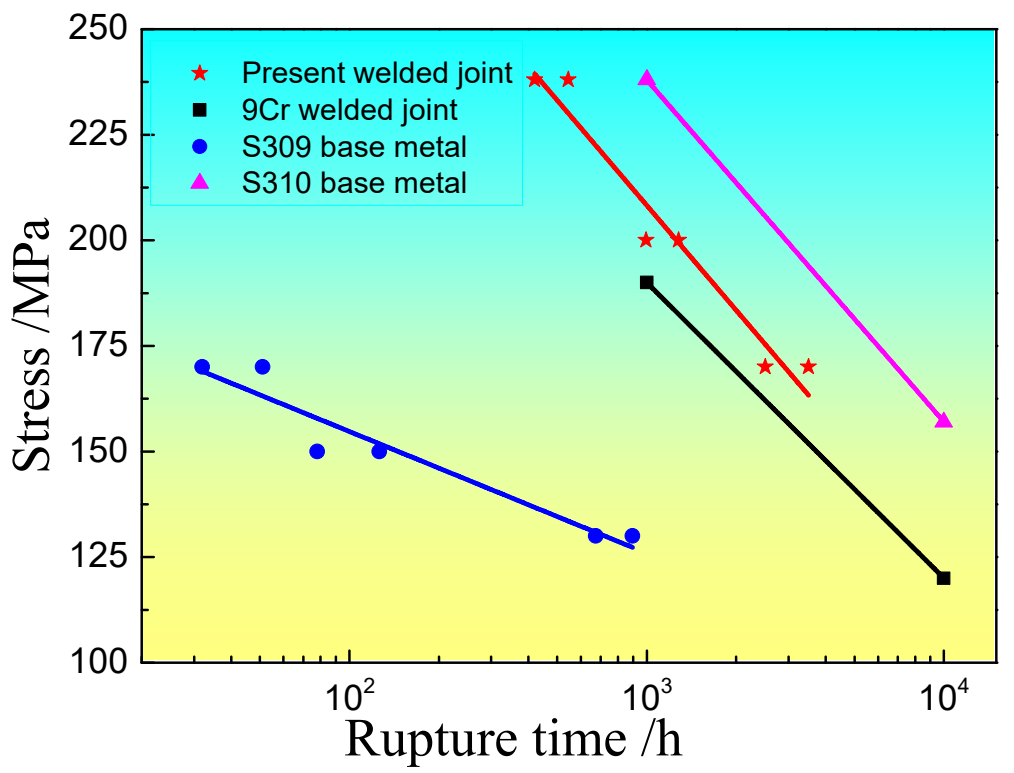

Figure 3. Creep rupture of the welded joints at $600{ }^{\circ} \mathrm{C}$ including $9 \mathrm{Cr}$ welded joint [27], S309 base metal [28] and S310 base metal [28].

Creep rupture tests were further conducted at $600{ }^{\circ} \mathrm{C}$ under stresses of $238 \mathrm{MPa}$ and $170 \mathrm{MPa}$, respectively. After the creep tests, the creep lives were determined to be $430 \mathrm{~h}$ and $3504 \mathrm{~h}$, respectively. Figure 4 shows the macroscopic and microscopic profiles of the $310 \mathrm{~S}$ weld after creep rupture. The fracture location is visible in the HAZ of the welded joints. In the rupture specimen, creep deformation and necking phenomena were not observed under the stress of $238 \mathrm{MPa}$, as shown in Figure $4 \mathrm{a}, \mathrm{b}$. To reveal the cracking evolution during the creep process, the microstructure of the creep fracture is shown in Figure 4c. It can be seen that many secondary cracks appear in the HAZ, which should be responsible for the creep 
rupture. Cracking is generated from the micro-cracks that form along the austenite grain boundaries, and its direction tends to be perpendicular to the loading direction, as shown in Figure 4c.
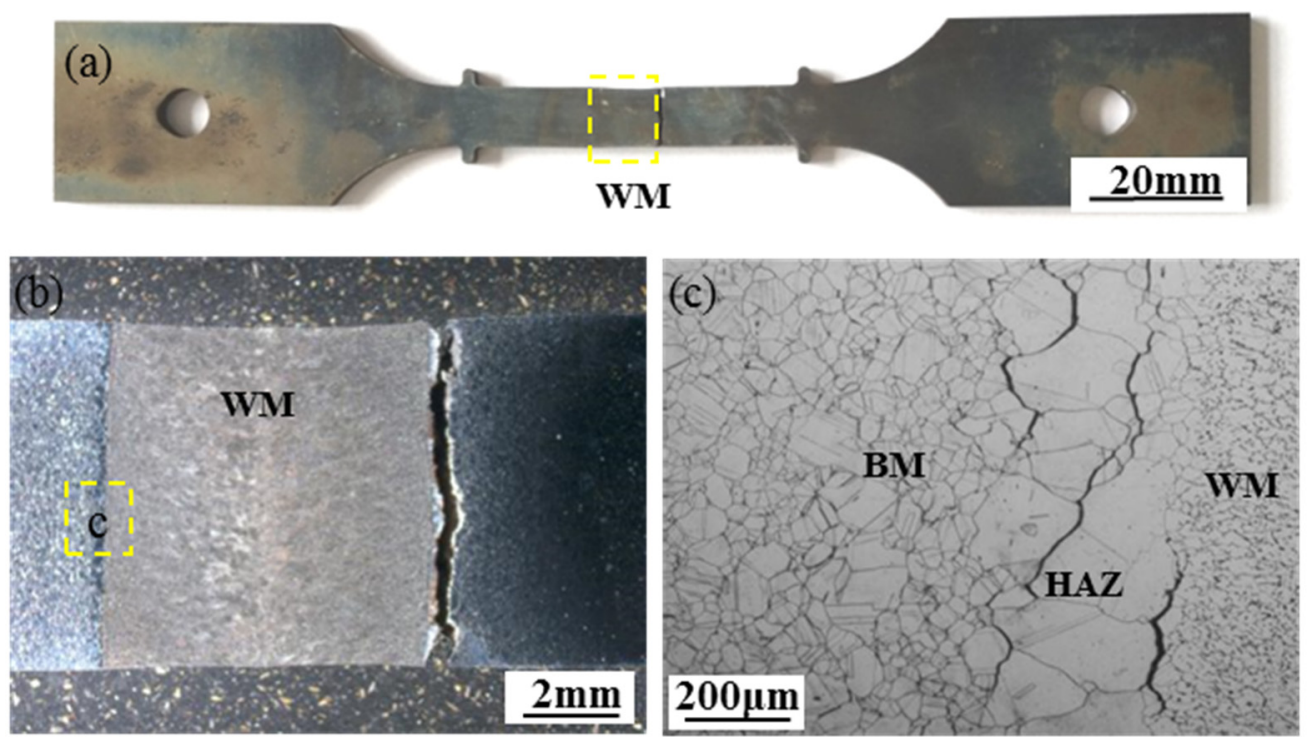

Figure 4. Fracture morphology of the creep rupture specimens at $600{ }^{\circ} \mathrm{C}$ under $238 \mathrm{MPa}$ stress for $430 \mathrm{~h}:(\mathbf{a}, \mathbf{b})$ macroscopic morphology of the creep fracture; (c) amplified fracture of HAZ.

Long term service at a high temperature induces stress relaxation cracking (SRC) in the heat affected zone of the austenitic stainless steel [29]. Figure 5 shows the fracture morphologies of two creeps rupture specimens at $600{ }^{\circ} \mathrm{C}$ under $238 \mathrm{MPa}$ and $170 \mathrm{MPa}$, as observed by SEM. Figure 5a shows the macro-profile of the specimen under $238 \mathrm{MPa}$ for $430 \mathrm{~h}$. A large cavity is observed on the fracture in Figure 5b. The cavities are apt to form cracks and accelerate the cracking during creep. Few dimples are found around the cavities, and it can be concluded that the fracture is mixed type under $238 \mathrm{MPa}$. Figure $5 \mathrm{c}, \mathrm{d}$ present the fracture features of the long-term specimen subjected to $170 \mathrm{MPa}$ for $3504 \mathrm{~h}$. The fracture has a smooth edge and gray particles adhere to its surface. The fracture type is estimated as mixed type fracture with less ductility. Intergranular cracks could be found on the fracture of the long term creep specimen. It was reported that cracks are easier to initiate and propagate along the noncoherent $\mathrm{M}_{23} \mathrm{C}_{6} / \gamma$ interface [30]. Consequently, the cracks grew and coalesced to form intergranular cracking under the creep service.

Given that creep cracking is dominated by stress, failure should occur in the lowerresistance creep section. In general, the hardness value is positively correlated with the resistance to plastic deformation [27]. Figure 6 illustrates the micro-hardness results of the welded joint. It can be seen that the micro-hardness value gradually decreases as the distance increases from the WM center. The maximum micro-hardness value of $198 \mathrm{HV}$ appears in the WM. As the distance increases, the micro-hardness decreases from the WM center, while the HAZ presents the lowest micro-hardness value of $178 \mathrm{HV}$. Compared with the micro-hardness of the welded joint, the fracture location is considered as HAZ. 

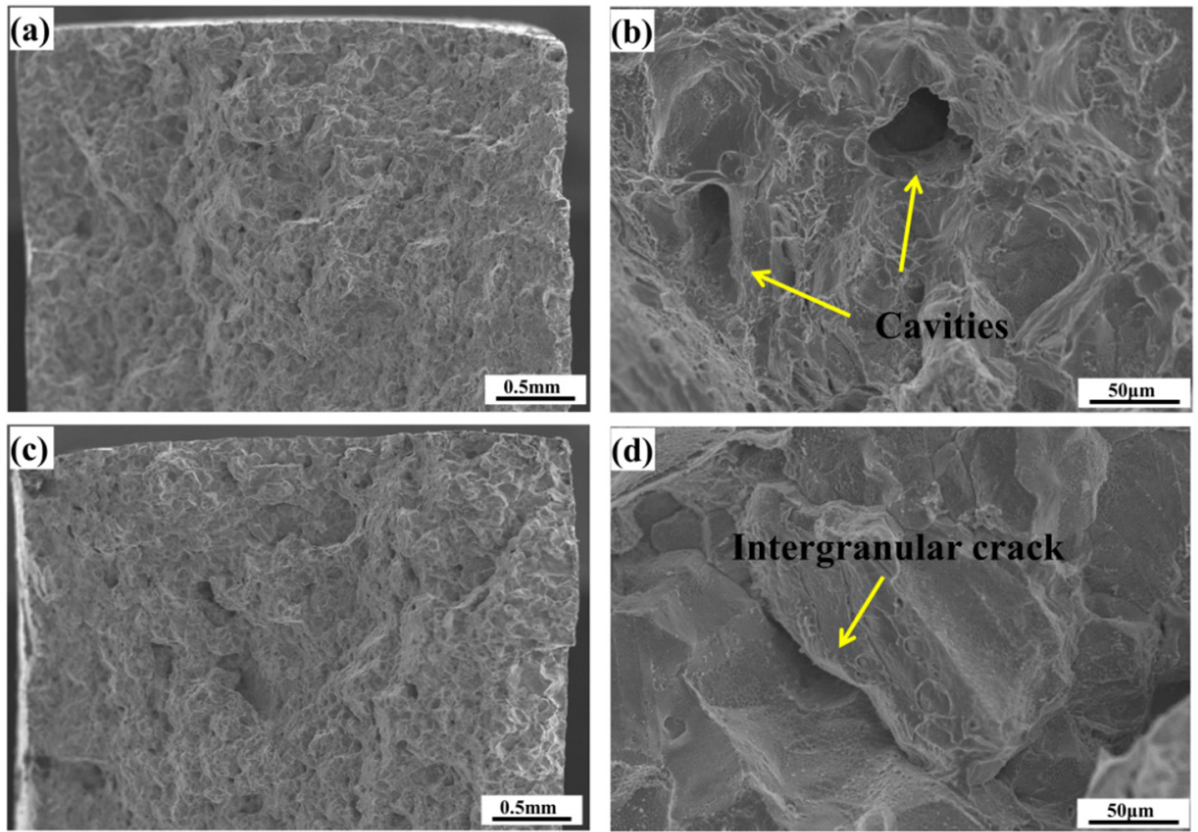

Figure 5. Fracture morphology of the creep rupture specimens: (a) macroscopic morphology under $238 \mathrm{MPa}$, (b) the amplified fracture surfaces of (a), (c) the macroscopic morphology under $170 \mathrm{MPa}$, (d) the amplified fracture surfaces of (c).

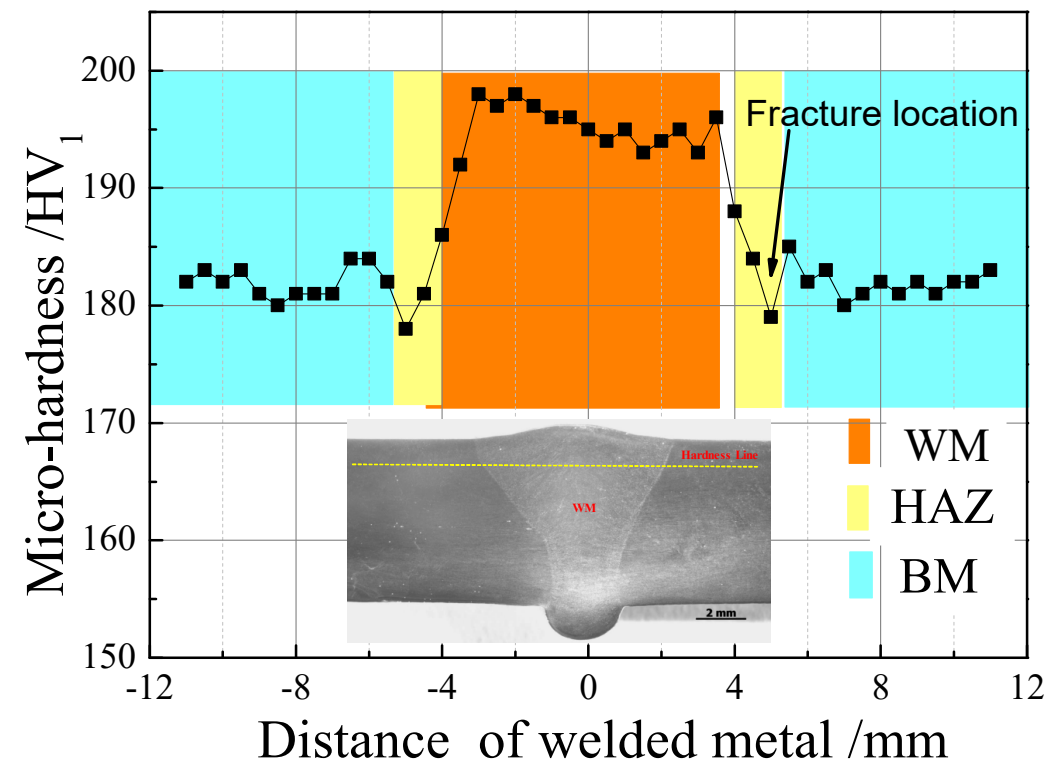

Figure 6. Micro-hardness distribution of the as received welded joint.

\subsection{Cracking and Failure Evolution}

In order to better understand crack initiation and propagation in the $310 \mathrm{~S}$ welded joint, the microstructure near the creep fracture is shown in Figure 7. It can be seen from Figure 7a that some cavities are distributed along the grain boundaries, especially at triple points, where the stress concentration is bound to emerge. As shown in Figure $7 \mathrm{c}$, the cracks are typically intergranular micro-cracks. Moreover, there are abundant brittle phases of $\mathrm{M}_{23} \mathrm{C}_{6}$ and $\delta$-ferrite along the grain boundary, as shown in Figure $7 \mathrm{~d}$. It should be noted that the existence of $\mathrm{M}_{23} \mathrm{C}_{6}$ and $\delta$-ferrite could deteriorate the creep properties of the welded joints. At the same time, the cavities nucleate around the carbides due to the difference in the deformation resistance between the low-stability $\mathrm{M}_{23} \mathrm{C}_{6}$ and the matrix. Upon the initiation of the creep process, the cavities are propagated and extended into cracks along the grain 
boundary, where they separate from discontinuous $\mathrm{M}_{23} \mathrm{C}_{6}$. Finally, the intergranular cracks converge, as shown in Figure $7 \mathrm{~b}$.
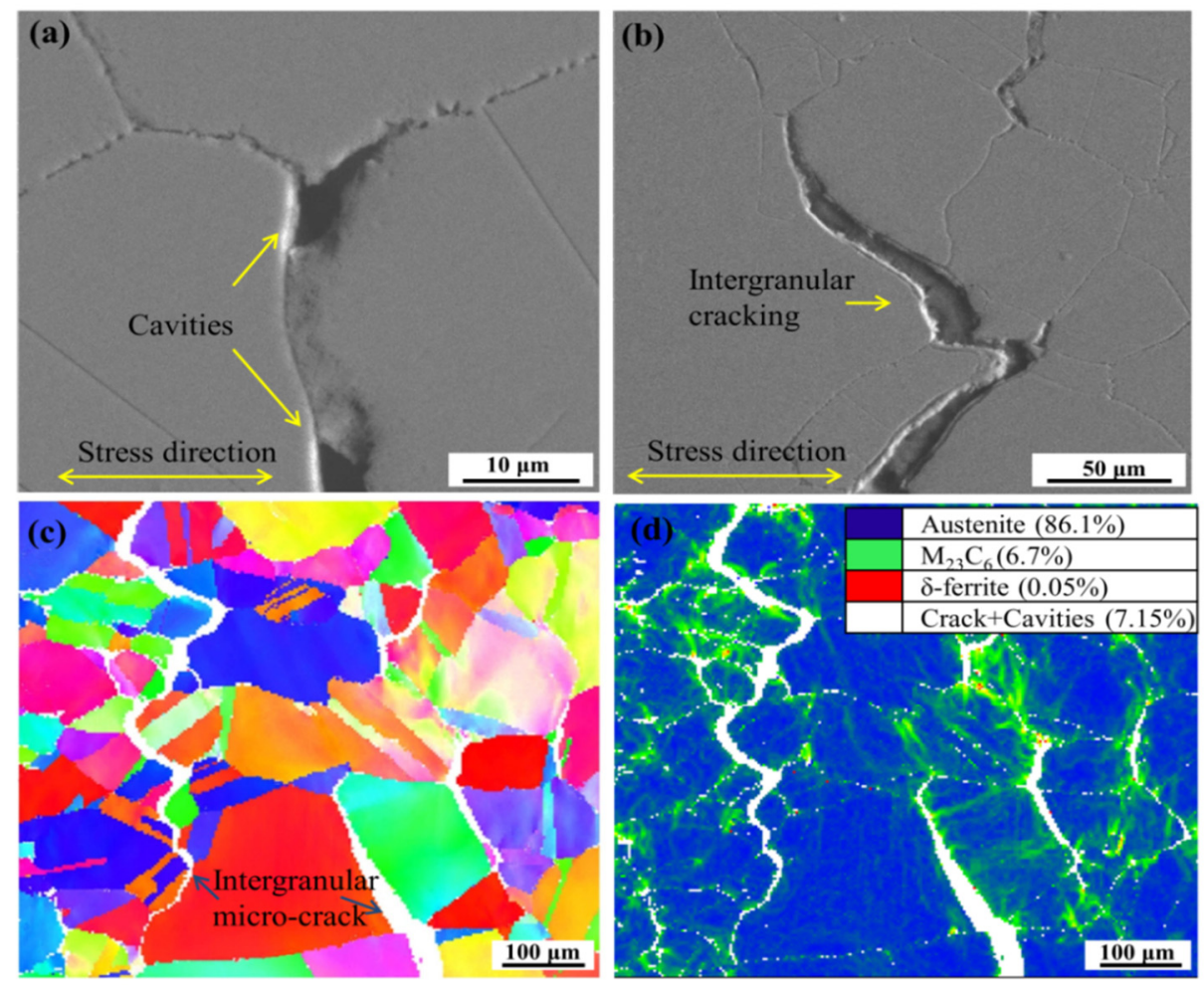

Figure 7. Microstructure near creep rupture: (a) cavities; (b) intergranular cracking; (c) EBSD analysis of intergranular crack; (d) phase distribution of (c).

\subsection{Microstructure Evolution during Creep Exposure}

To visualize and quantify the microstructure evolutions across the welded joints, the EBSD results for the creep specimens are shown in Figure 8. It can be used for evaluating creep damage from the EBSD measurement. The normal directions parallel to the crystal orientations are shown in Figure 8(a1-a3) as the inverse pole figure (IPF) maps. The local misorientation of the welded joint, assessed by kernel average misorientation (KAM), is shown in Figure $8(\mathrm{~b} 1-\mathrm{b} 3)$. In the HAZ, higher KAM values $\left(0.80^{\circ}\right)$ indicate a greater crystallographic orientation, resulting in the difference in deformation resistance. As a result, the nucleation of cavities in the HAZ is accelerated. The WM shows the lowest KAM value $\left(0.50^{\circ}\right)$ owing to the reduced precipitate strength effect induced by recrystallization. Wang et al. reported that precipitates contribute to promoting the formation of creep cracks around the grain boundary [31]. Hence, the microstructures of grain boundaries play an important role in inducing creep cracking. Accordingly, the mechanical property is closely related to grain boundary characteristics, as assessed by coincidence site lattice (CSLs) theory, which has been successfully applied in improving materials' performance $[32,33]$. The grain boundary distribution (GBD) characteristics, especially twin (sigma 3), are also shown in Figures 4 and 8(c1-c3). Due to the long-term service high stress at elevated temperatures conditions and the varying welding thermal field, the twin boundary distributions in each zone are clearly distinguished. The twin (sigma 3 ) grain boundaries account for more than half of the content $(53.1 \%$ ) in the BM. The proportion of twin (sigma 3) boundaries in the HAZ is lower (36.8\%) than that in the BM. Although the twin grain boundaries represent only $15.8 \%$ of the WM, a high alloy element could play the role of alloy strengthening. 

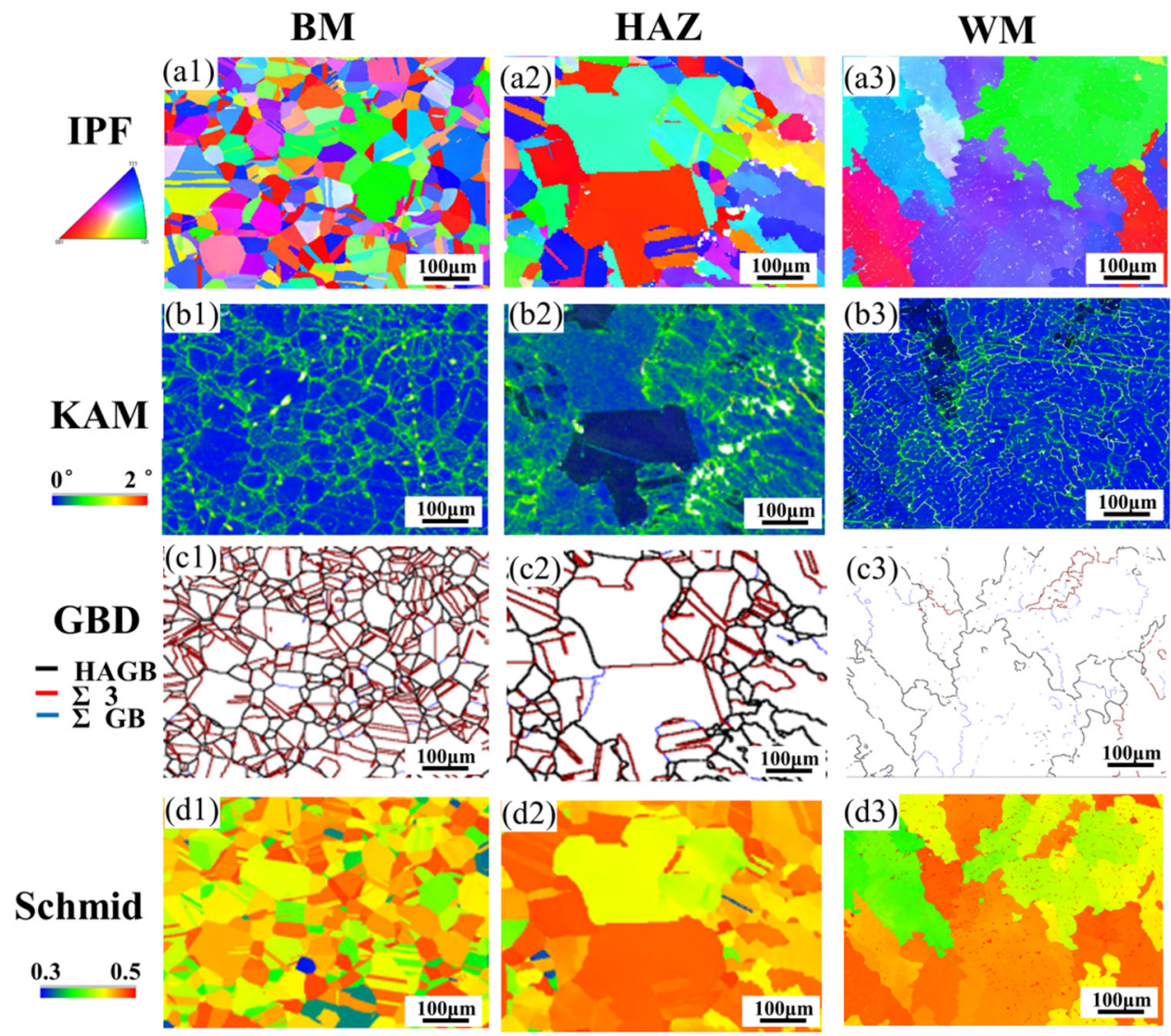

Figure 8. EBSD analysis of BM, WM and HAZ for the creep specimen marked in Figure 4a: (a1-a3) inverse pole figure (IPF); (b1-b3) kernel average misorientation (KAM); (c1-c3) grain boundary distribution (GBD); and (d1-d3) Schmid factor.

Schmid factor maps were used to further analyze the creep deformation behaviors, as shown in Figure 8(d1-d3). The Schmid factor is used to evaluate the slip resistance of multi-crystal materials. As is well known, a lower slip energy is needed to induce a higher Schmid factor [34]. Compared with BM and WM, HAZ presents a higher Schmid factor in welded joints, thus HAZ deformation requires less work. A higher Schmid factor indicates a bigger shear stress between grains in the deformation. The deformations are different in each section of the welded joints, which gives rise to a different Schmid factor in the weld metal, base metal and HAZ. The cracks were usually nucleated in the grain with a high Schmid factor, which demonstrates that the grain is easy to deform. As a result, intergranular cracks tend to appear between grains with high Schmid factors and those with low Schmid factors. Overall, by comparing the key structural characteristics of IPF, KAM, GBD and Schmid factor, the HAZ shows the lowest creep resistance in the welded joint, which is in accordance with the results shown in Figure 4.

In order to clarify the effect of microstructure evolution on the creep failure behavior, TEM was applied to characterize the $\delta$-ferrite and $\gamma$-austenite grain boundaries in the WM, $\mathrm{HAZ}$ and BM of the specimens. Figure 9 shows that the grain boundary between $\delta$-ferrite and $\gamma$-austenite is discontinuous and decorated with Laves phases in the WM. Furthermore, the details of the boundary show that $\mathrm{M}_{23} \mathrm{C}_{6}$ carbides are precipitated along the grain boundary and a great many dislocations are also detected near the grain boundary, which would significantly contribute to dislocation strength. As the filler material has a higher Mo content ( $0.35 \mathrm{wt} . \%)$ than BM $(0.05 \mathrm{wt} . \%)$, such difference may lead to the formation of Laves phases in WM [23]. The composition and SAED pattern in Figure 9a also confirmed it was the Laves phase. This means that the accumulation of the Laves phases in WM plays a significant role in precipitation strengthening during the creep process. 

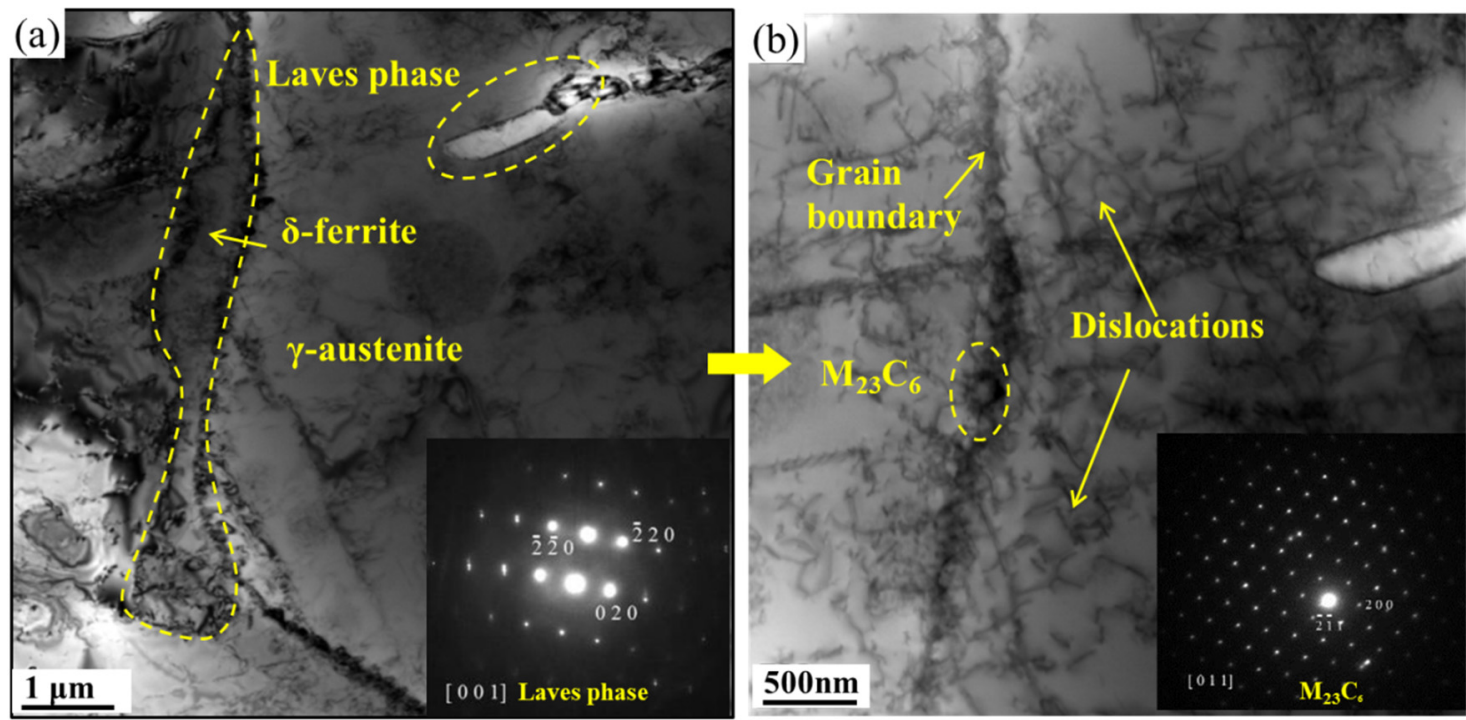

Figure 9. TEM characterization of the creep sample in WM: (a) $\delta / \gamma$ boundary (b) detailed boundary.

The microstructures were analyzed to clarify the failure location characteristic of HAZ. Figure 10 shows the TEM measurement of the creep sample in the HAZ. It can be seen that more second phases are distributed along the grain boundary of the prior austenite, and especially precipitated in the intersection of the triple grain boundaries. The distribution of elements was also assessed by EDS mapping near the triple grain boundary. As shown in Figure 11, the segregation of $\mathrm{Cr}, \mathrm{Ni}, \mathrm{Ce}, \mathrm{Mn}$ and $\mathrm{N}$ is visible around the grain boundary. Chemical composition analysis of phases was performed by atom probe tomogram APT. Round rods with a diameter of $500 \mu \mathrm{m}$ and a length of $15 \mathrm{~mm}$ were cut from the HAZ and ground to remove the oxide scale. For the sample subjected to $\mathrm{HAZ}$, the segregation of $\mathrm{Cr}$, $\mathrm{C}$ atoms can be clearly observed in the analysis volume from Figure 12. Further, Figure 12 reveals $\mathrm{Cr}$ and $\mathrm{C}$-rich cores shells near the grain boundary. The concentration profile indicates peaks of $\mathrm{Cr}, \mathrm{C}$ concentration, about 64 at.\%, 8 at.\%, respectively, and poor of $\mathrm{Fe}, \mathrm{Ni}$ and $\mathrm{Si}$ at the core. As expected, brittle phases and element segregations are detected in the triple grain boundary as a result of the high cooling rate in the PAW; however, the formation of these detrimental structures usually leads to crack initiation during the original stage of the creep process. Compared with WM, HAZ enables discrepant deformation in both the heterogeneous coarse grains and the brittle phases, leading to a more regular defect. Besides this, the formation of considerably coarsened $\mathrm{M}_{23} \mathrm{C}_{6}$ during long-term creeping is detrimental to the tensile property. Further, with the increase of the in creep time, more cracks accumulate around the brittle phases along the grain boundaries, which eventually lead to creep fracture in the HAZ.

Figure 13 shows representative TEM micrographs of the BM derived from creep samples. It can be observed in Figure 13a that twin microstructures and dislocations are formed around the grain boundaries. On the one hand, low-stacking fault energy metals have great potential to form twin microstructures owing to the deforming and annealing process [35]. As for low-mobility and low-segregation strengthening alloys, the twin microstructure plays a significant role in affecting the serving properties. On the other hand, due to the crystallographic symmetry, coherent twin boundaries have a strong mechanical strengthening effect without deteriorating other properties [35]. As shown in Figure 13b, the interaction of the dislocation and Cr-rich phase is evident. As a result, misfitted dislocations around the precipitates and entangled dislocations are also observed in the BM zone. According to the Orowan passing and cutting theory, the dislocation motion is impeded by the second phases, which in turn strengthens the precipitation $[34,36]$. Under such conditions, this feature explains the commonly observed Orowan dislocation loop around the second phases, which varies with the content of the second phases. The second 
phases are not sheared by the dislocation, while the passing mechanism plays a leading role. On the contrary, the cutting mechanism is always dominant if the precipitation is small enough. As shown in Figure 14, the Cr-rich, Ce, and Mn phases are easily observed around the dislocations.
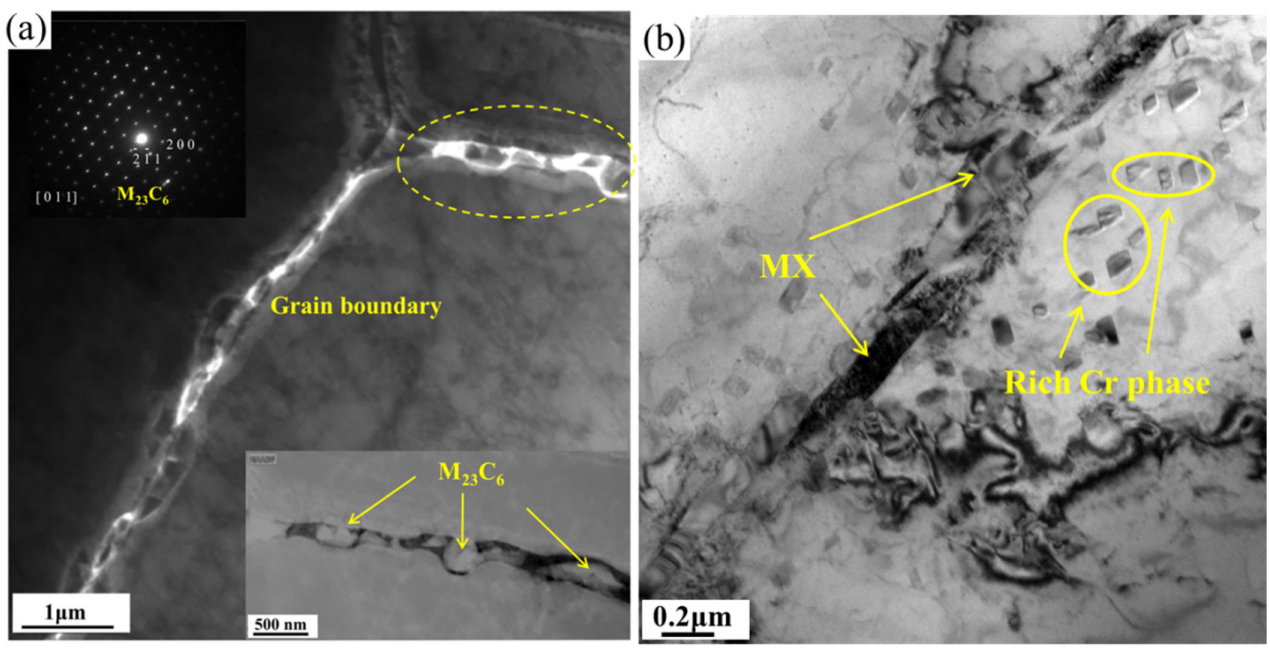

Figure 10. TEM characterization of the creep sample in HAZ (a) triple grain boundary $(\mathbf{b})$ twin grain boundary.


Figure 11. EDS of grain boundary of the creep sample in HAZ. 

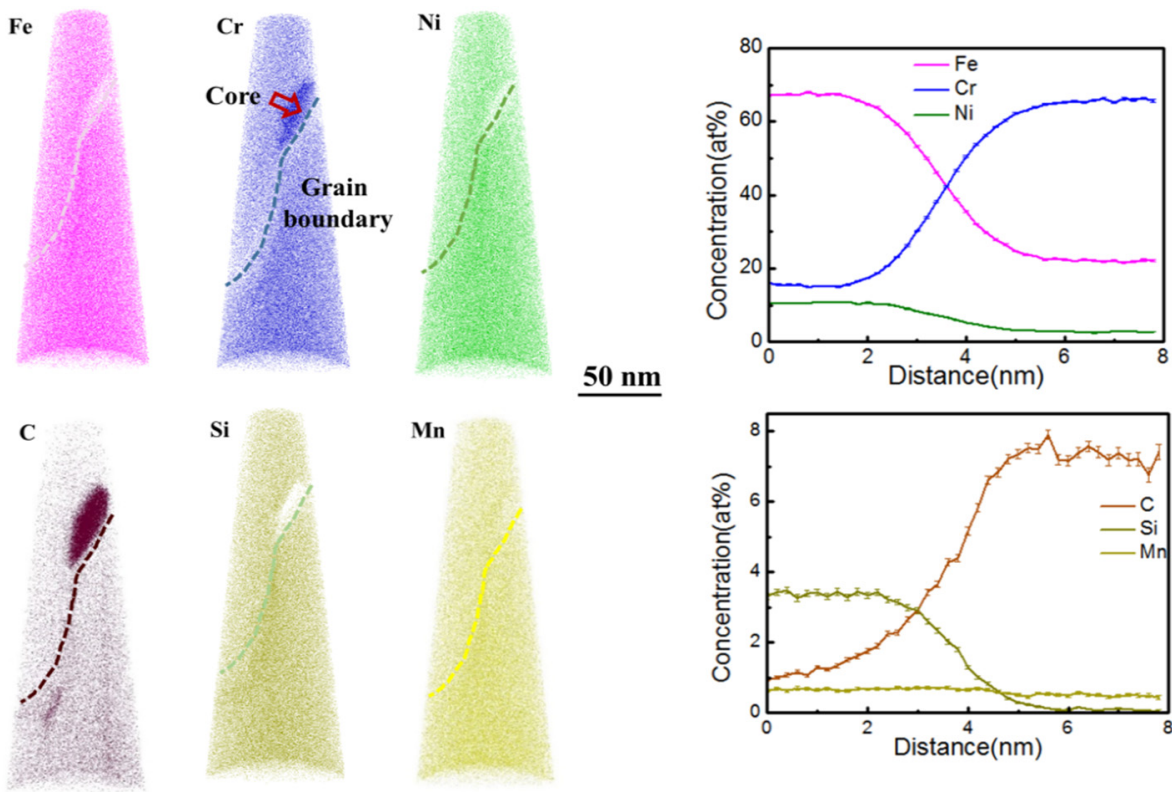

Mn

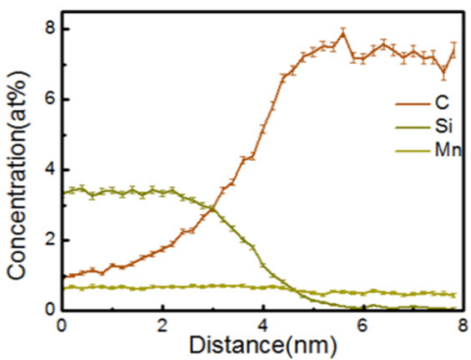

Figure 12. Atomic probe maps and concentration profile of the sample subjected to HAZ.
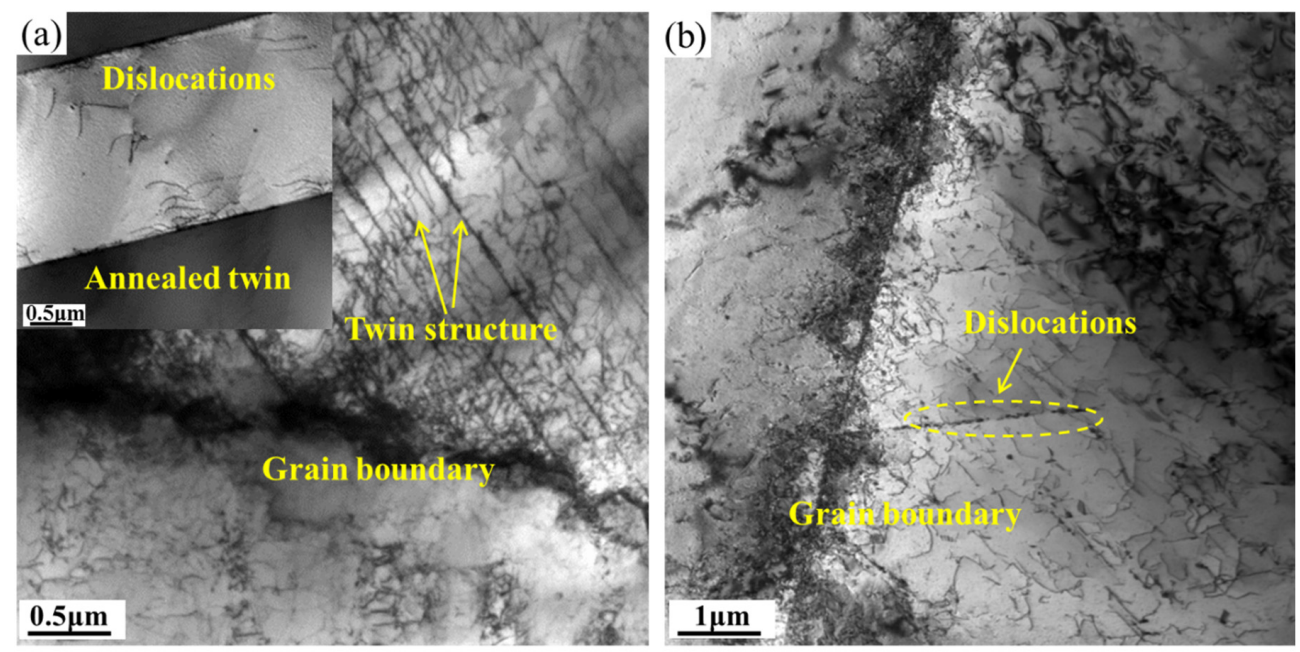

Figure 13. TEM observation of the creep sample in BM: (a) twin grain; (b) dislocation.
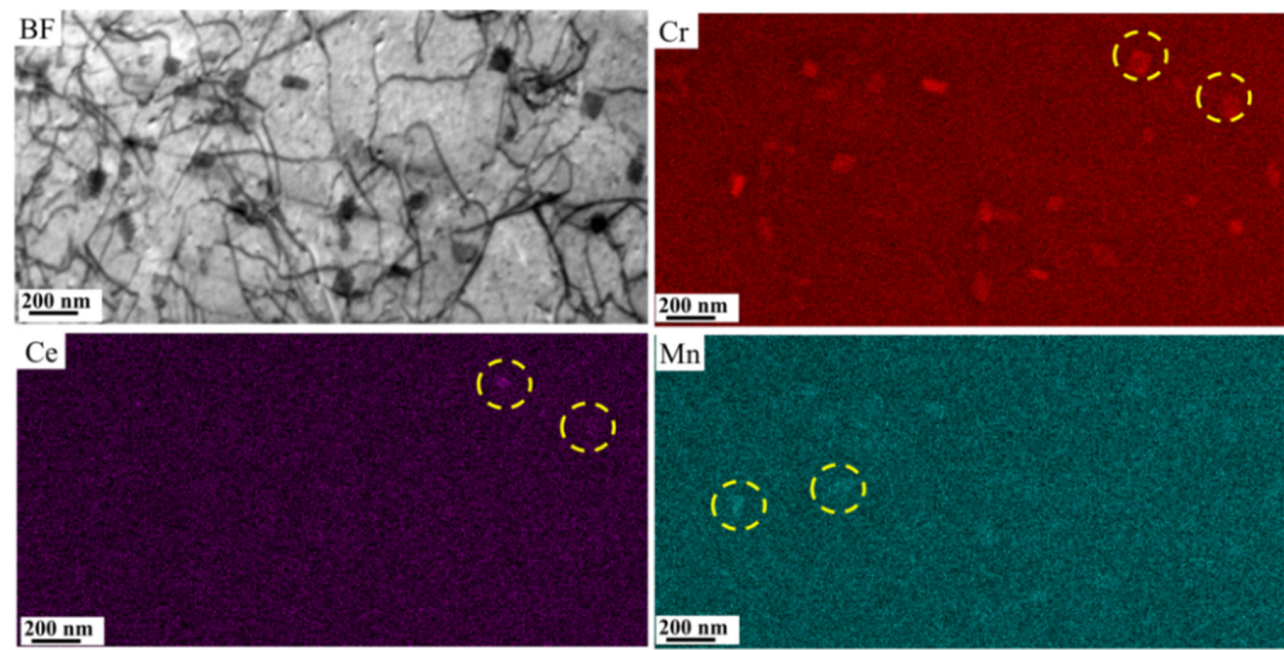

Figure 14. EDS of the grain boundary of the creep sample in BM. 
It is worth mentioning that a physics-based constructive model for the strengthening mechanism can be constructed to predict the critical stress $(T)$ during the creep process. As such, the $T$ needs to bend a dislocation between two precipitations $\left(T_{p 2}\right)$ or three precipitations $\left(T_{p 3}\right)$, which can be shown as follows $[37,38]$ :

$$
\begin{gathered}
T_{P 2}=1+M_{1}^{1 / 2}+M_{2}^{1 / 2}+\frac{1}{8}\left(M_{1}^{1 / 4}+M_{2}^{1 / 4}\right)^{4} \\
T_{P 3}=1+\left(M_{1}^{1 / 2}+M_{2}^{1 / 2}+M_{3}^{1 / 2}\right)+\frac{1}{8}\left(M_{1}^{1 / 4}+M_{2}^{1 / 4}+M_{3}^{1 / 4}\right)^{4} \\
M_{i}=K\left(G b^{2} / \varepsilon_{l}\right) N_{i}\left(r_{i} / \lambda\right)^{2}, i=1,2,3
\end{gathered}
$$

where $K=1+v / 2(1-v), G$ is the shear modulus, $b$ is Burger's vector, $\varepsilon$ is the dislocation line tension, $N$ is the dislocation loop, $r$ is the mean area of the Orowan loops, and $\lambda$ is the space of the particles.

In this study, the threshold value of creep stress at $923 \mathrm{~K}$ for the Fe-22Cr-15Ni steel weldment is $115 \mathrm{MPa}$ and $132 \mathrm{MPa}$, corresponding with the double and triple precipitation models, respectively [38]. The double case model calculates the stresses at about $136 \mathrm{MPa}$ and $164 \mathrm{MPa}$ for the modified $310 \mathrm{~S}$ austenitic stainless steel welded joint at $600{ }^{\circ} \mathrm{C}$. The back-stress can be evaluated using a hypothetical model for modified $310 \mathrm{~S}$ stainless steel during the creep process.

As reported by Maruyama et al. [39], precipitated particles with small sizes and dispersive distributions usually play a role in significant precipitation strengthening, which can be employed in the creep failure response. The discontinuously precipitated particles appeared both on grain boundaries and inside grains can obstruct the dislocation, generating a distinct pinning strengthening effect during the initial stage of the creep process. However, when the creep process enters the stable stage, the precipitated particles begin to grow and connect with each other to produce a weakened layer, especially bulky $\mathrm{M}_{23} \mathrm{C}_{6}$ particles. As a result, the strengthening effect is reduced, as validated by Maruyama et al. [39]. Moreover, the precipitation of intergranular and $\mathrm{M}_{23} \mathrm{C}_{6}$ carbides retarding the occurrence of necking is detrimental to the ductility of the material. According to Tian et al., post-weld heat treatment at $690{ }^{\circ} \mathrm{C}$ for $8 \mathrm{~h}$ could improve the strength of the welded joint [40]. The ductility reduction during the primary creep was mainly caused by the grain boundary failure and element separation resulting from the carbide precipitation. As the creep proceeded, the $\mathrm{M}_{23} \mathrm{C}_{6}$ significantly coarsened along the boundary in the HAZ (Figure 10). According to in situ DIC, the most severe creep deformation occurred in the HAZ. The maximum strain $(6.8 \%)$ could be as much as three times the average strain in the HAZ. Meanwhile, the hysteresis energy density (HED) in the HAZ could reach 10 times that in the BM [41]. Meanwhile, both intergranular cracks were found on the fracture surface (Figure 5d). According to Jiang et al. [42], cavities nucleate at the unstable incoherent precipitation interfaces and propagate into the micro-cracks near grain boundaries. The creep failure behavior of a welded joint is intergranular cracking, initiated around the coarsened $\mathrm{M}_{23} \mathrm{C}_{6}$ carbides at the HAZ boundary and propagating along it [16].

In order to clarify the failure behavior of the welded joints, the creep failure behavior is illustrated in Figure 15. According to the above results, creep failure preferentially occurs in the HAZ. This is because HAZ has a lower resistance to creep deformation as a result of its lower micro-hardness and dislocation density (see Figures 4,6 and 10). At the same time, the HAZ also experiences high temperatures during the welding process. A high temperature can greatly accelerate second phase precipitation. In this case, creep resistance is obviously reduced, while KAM is increased. The coarsened precipitates, especially those appearing at the triple grain boundary (see Figure 10), tend to block the dislocation movements and decrease the harmonious conditions persisting throughout the high stress and temperature during the creep process. These inharmonious movements also accelerate the nucleation of creep cavities. Interestingly, micro-cavities are usually 
formed at the intersection of grain boundaries and extend along them. Accordingly, more cavities contribute to an increase in true stress. Considering the sustained endurance of the stress and high temperatures effect during the creep process, these micro-cavities often coalesce with each other to form micro-cracks along the grain boundaries. Eventually, the micro-cracks proliferate along the grain boundaries and generate intergranular cracks, resulting in the creep failure of the welded joints.
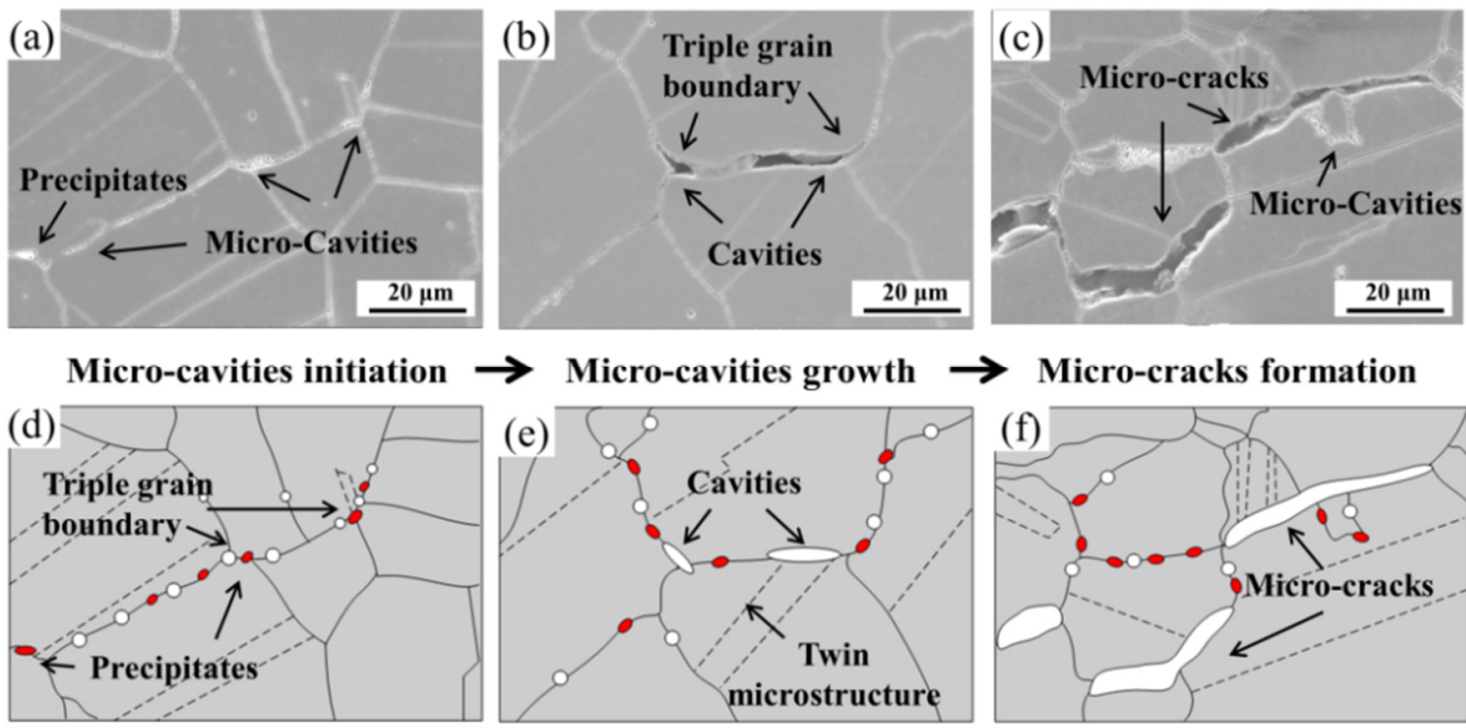

Figure 15. Schematic of the creep rupture behavior: $(\mathbf{a}, \mathbf{d})$ micro-cavities nucleation around the triple grain boundary and precipitates; (b,e) micro-cavities growth and coalescence; $(\mathbf{c}, \mathbf{f})$ micro-cavities form cracks.

\section{Conclusions}

(1) The creep failure behavior of modified $310 \mathrm{~S}$ stainless steel welded joints was analyzed from the microstructure, precipitated phase and dislocation perspectives. Compared with WM, the microstructure of HAZ is highly inhomogeneous, with coarsening grains and lower creep resistances, which result in creep rupture in the HAZ.

(2) The preferred nucleation around the precipitations and propagation along the grain boundaries of creep cavities lead to intergranular fracture. The higher KAM and Schmid factor and lower GBD are considered the key reasons for the lowest creep resistance being found in the HAZ of the welded joint.

(3) In the creep servicing, coarsened $\mathrm{M}_{23} \mathrm{C}_{6}$, grain heterogeneity and element segregation near the grain boundary often appeared in the HAZ, which is the source of crack initiation and detrimental to tensile strength. As the creep process proceeds, more cracks propagate around the second phase along the grain boundaries, leading to intergranular cracking.

Author Contributions: Conceptualization, Y.J.; data curation, Y.J.; methodology, Y.J.; data analysis, Y.J. and Y.K.; writing-original draft preparation, Y.J.; writing-review and editing, Y.K. and H.C.; supervision, H.C.; final approval, H.C.; project administration, H.C.; funding acquisition, Y.J. and H.C. All authors have read and agreed to the published version of the manuscript.

Funding: This research was funded by LingChuang Research Project of China National Nuclear Corporation.

Data Availability Statement: The data presented in this study are available on request from the corresponding author.

Acknowledgments: The authors would like to acknowledge the financial support provide by LingChuang Research Project of China National Nuclear Corporation. The authors are grateful 
to the supply of the stainless steel and welded joint samples from Erzhong (Deyang) Heavy Equipment Co., Ltd. and Gang Sha of the Nanjing University of Science and Technology for performing the APT analysis.

Conflicts of Interest: The authors declare no conflict of interest.

\section{References}

1. Liu, Z.; He, Y.; Gao, W. Surface nanocrystallization of 310s stainless steel and its effect on oxidation behavior. J. Mater. Eng. Perform. 1998, 7, 88-92. [CrossRef]

2. Lo, K.H.; Shek, C.H.; Lai, J.K.L. Recent developments in stainless steels. Mater. Sci. Eng. R Rep. 2009, 65, 39-104. [CrossRef]

3. Amirkhiz, B.S.; Xu, S.; Scott, C. Microstructural assessment of $310 \mathrm{~S}$ stainless steel during creep at $800{ }^{\circ} \mathrm{C}$. Materialia $2019,6,100330$. [CrossRef]

4. Farooq, M.; Sandström, R.; Lundberg, M. Precipitation during long time ageing in the austenitic stainless steel 310. Mater. High Temp. 2012, 29, 8-16. [CrossRef]

5. Meng, D.; Lu, F.; Cui, H.; Ding, Y.; Tang, X.; Huo, X. Investigation on creep behavior of welded joint of advanced $9 \%$ Cr steels. J. Mater. Res. 2014, 30, 197-205. [CrossRef]

6. Lee, E.; Byun, T.; Hunn, J.; Yoo, M.; Farrell, K.; Mansur, L. On the origin of deformation microstructures in austenitic stainless steel: Part I-microstructures. Acta Mater. 2001, 49, 3269-3276. [CrossRef]

7. Sourmail, T. Precipitation in creep resistant austenitic stainless steels. Mater. Sci. Technol. 2001, 17, 1-14. [CrossRef]

8. Zhu, S.; Yang, M.; Song, X.; Tang, S.; Xiang, Z. Characterisation of Laves phase precipitation and its correlation to creep rupture strength of ferritic steels. Mater. Charact. 2014, 98, 60-65. [CrossRef]

9. Gao, Q.; Wang, C.; Qu, F.; Wang, Y.; Qiao, Z. Martensite transformation kinetics in 9Cr-1.7W-0.4Mo-Co ferritic steel. J. Alloys Compd. 2014, 610, 322-330. [CrossRef]

10. West, D.; Hulance, J.; Higginson, R.; Wilcox, G.D. $\sigma$-Phase precipitation in 347HFG stainless steel. Mater. Sci. Technol. 2013, 29, 835-842. [CrossRef]

11. Wang, Z.-N.; Liang, T.; Xing, W.-W.; Du, A.-B.; Gao, M.; Ma, Y.-C.; Liu, K. $\sigma$-Phase Precipitation Mechanism of 15Cr-15Ni Titanium-Modified Austenitic Stainless Steel During Long-Term Thermal Exposure. Acta Met. Sin. (Engl. Lett.) 2018, 31, 281-289. [CrossRef]

12. Öberg, C.; Zhu, B.; Jonsson, S. Creep behaviour, creep damage and precipitation in the austenitic cast steel HK30 at $750{ }^{\circ} \mathrm{C}$. Mater. Sci. Eng. A 2020, 797, 140253. [CrossRef]

13. Hu, G.; Wang, P.; Li, D.; Li, Y. High-temperature Tensile Behavior in Coarse-grained and Fine-grained Nb-containing 25Cr-20Ni Austenitic Stainless Steel. Acta Met. Sin. (Engl. Lett.) 2020, 33, 1455-1465. [CrossRef]

14. Zhang, W.; Zhang, T.; Wang, X.; Chen, H.; Gong, J. Remaining creep properties and fracture behaviour of P92 steel welded joint under prior low cycle fatigue loading. J. Mater. Res. Technol. 2020, 9, 7887-7899. [CrossRef]

15. Sroka, M.; Zieliński, A.; Golański, G.; Kremzer, M. The Influence of Long-term Ageing on the Microstructure of Sanicro 25 Steel In Proceedings of the MATEC Web of Conferences, Sibiu, Romania, 5-7 June 2019; Volume 253.

16. Li, Y.; Fan, X.; Cui, H.; Lu, F.; Tang, X. The correlated mechanism of creep fracture and microstructure evolution for precipitated Nimonic 263 superalloy welding joint. Sci. Technol. Weld. Join. 2021, 26, 37-46. [CrossRef]

17. Gonzaga, A.; Barbosa, C.; Tavares, S.; Zeemann, A.; Payão, J. Influence of post welding heat treatments on sensitization of AISI 347 stainless steel welded joints. J. Mater. Res. Technol. 2020, 9, 908-921. [CrossRef]

18. Kaneko, K.; Fukunaga, T.; Yamada, K.; Nakada, N.; Kikuchi, M.; Saghi, Z.; Barnard, J.S.; Midgley, P.A. Formation of M23C6-type precipitates and chromium-depleted zones in austenite stainless steel. Scr. Mater. 2011, 65, 509-512. [CrossRef]

19. Lim, Y.S.; Kim, D.J.; Hwang, S.S.; Kim, H.P.; Kim, S.W. M23C6 precipitation behavior and grain boundary serration in Ni-based Alloy 690. Mater. Charact. 2014, 96, 28-39. [CrossRef]

20. Zheng, L.; Hu, X.; Kang, X.; Li, D. Precipitation of M23C6 and its effect on tensile properties of $0.3 \mathrm{C}-20 \mathrm{Cr}-11 \mathrm{Mn}-1 \mathrm{Mo}-0.35 \mathrm{~N}$ steel. Mater. Des. 2015, 78, 42-50. [CrossRef]

21. Sawada, K.; Hara, T.; Tabuchi, M.; Kimura, K.; Kubushiro, K. Microstructure characterization of heat affected zone after welding in Mod.9Cr-1Mo steel. Mater. Charact. 2015, 101, 106-113. [CrossRef]

22. Isik, M.; Kostka, A.; Yardley, V.; Pradeep, K.; Duarte, M.; Choi, P.; Raabe, D.; Eggeler, G. The nucleation of Mo-rich Laves phase particles adjacent to M23C6 micrograin boundary carbides in 12\% Cr tempered martensite ferritic steels. Acta Mater. 2015, 90, 94-104. [CrossRef]

23. Isik, M.; Kostka, A.; Eggeler, G. On the nucleation of Laves phase particles during high-temperature exposure and creep of tempered martensite ferritic steels. Acta Mater. 2014, 81, 230-240. [CrossRef]

24. Liu, W.; Liu, X.; Lu, F.; Tang, X.; Cui, H.; Gao, Y. Creep behavior and microstructure evaluation of welded joint in dissimilar modified 9Cr-1Mo steels. Mater. Sci. Eng. A 2015, 644, 337-346. [CrossRef]

25. Kumar, Y.; Venugopal, S.; Sasikala, G.; Parida, P.; Moitra, A. Study of creep crack growth behaviour of a type 316(N) stainless steel weld and its mechanism. Mater. Sci. Eng. A 2018, 731, 551-560. [CrossRef]

26. Jordan, P.; Maharaj, C. Asset management strategy for HAZ cracking caused by sigma-phase and creep embrittlement in $304 \mathrm{H}$ stainless steel piping. Eng. Fail. Anal. 2020, 110, 104452. [CrossRef] 
27. Wei, Y.; Qiao, S.; Lu, F.; Liu, W. Failure transition mechanism in creep rupture of modified casting 9Cr-1.5Mo-1Co welded joint. Mater. Des. 2016, 97, 268-278. [CrossRef]

28. EN 10095-1999. British Standard; Heat Resisting Steels and Nickel Alloys. British Standards Committee: London, UK, 15 July 1999.

29. Chabaud-Reytier, M.; Allais, L.; Caes, C.; Dubuisson, P.; Pineau, A. Mechanisms of stress relief cracking in titanium stabilised austenitic stainless steel. J. Nucl. Mater. 2003, 323, 123-137. [CrossRef]

30. Xiao, X.; Li, D.; Li, Y.; Lu, S. Intergranular precipitation behavior and its influence on the stress relaxation cracking susceptibility of Super304H austenitic stainless steel weld metal during long-term aging. Mater. Charact. 2021, 178, 111309. [CrossRef]

31. Wang, Y.; Zhang, W.; Wang, Y.; Lim, Y.C.; Yu, X.; Feng, Z. Experimental evaluation of localized creep deformation in grade 91 steel weldments. Mater. Sci. Eng. A 2020, 799, 140356. [CrossRef]

32. Tan, L.; Allen, T.; Busby, J. Grain boundary engineering for structure materials of nuclear reactors. J. Nucl. Mater. 2013, 441, 661-666. [CrossRef]

33. Hirayama, K.; Yoshii, Y.; Morizono, Y.; Tsurekawa, S.; Hidaka, Y. Grain Boundary Engineering of 10\% Cr Ferritic-Martensitic Steel SUH3. ISIJ Int. 2015, 55, 1973-1979. [CrossRef]

34. Li, Y.; Wang, X. Strengthening mechanisms and creep rupture behavior of advanced austenitic heat resistant steel SA-213 S31035 for A-USC power plants. Mater. Sci. Eng. A 2020, 775, 138991. [CrossRef]

35. Lu, L.; Shen, Y.; Chen, X.; Qian, L.; Lu, K. Ultrahigh Strength and High Electrical Conductivity in Copper. Science 2004, 304, 422-426. [CrossRef] [PubMed]

36. Cooper, G.A. Strengthening Methods in Crystals; Kelly, A., Nicholson, R.B., Eds.; Elsevier: Amsterdam, The Netherlands; London, UK; New York, NY, USA, 1971; 627p.

37. Hart, E. Theory of dispersion hardening in metals. Acta Met. 1972, 20, 275-289. [CrossRef]

38. Zhang, Y.; Jing, H.; Xu, L.; Han, Y.; Zhao, L.; Xie, X.; Tang, Z. Fusion boundary evolution, precipitation behaviour, and interaction with dislocations in an Fe-22Cr-15Ni steel weldment during long-term creep. Prog. Nat. Sci. Mater. Int. 2019, 29, 41-49. [CrossRef]

39. Maruyama, K.; Sawada, K.; Koike, J.-I. Strengthening Mechanisms of Creep Resistant Tempered Martensitic Steel. ISIJ Int. 2001, 41, 641-653. [CrossRef]

40. Tian, W.; Wu, D.; Li, Y.; Lu, S. Precipitation Behavior and Mechanical Properties of a 16Cr-25Ni Superaustenitic Stainless Steel Weld Metal During Post-weld Heat Treatment. Acta Met. Sin. (Engl. Lett.) 2021, 1-14. [CrossRef]

41. Fan, M.; Shao, C.; Wang, Y.; Huo, X.; Ma, N.; Lu, F. In-situ DIC investigation on local stress-strain behavior in creep-fatigue test of dissimilar steel welded joint. Int. J. Fatigue 2021, 152, 106464. [CrossRef]

42. Jiang, J.; Zhu, L. Strengthening mechanisms of precipitates in S30432 heat-resistant steel during short-term aging. Mater. Sci. Eng. A 2012, 539, 170-176. [CrossRef] 